\title{
Investigating Predictors of Pre-service Science Teachers' Behavioral Intention toward e-Resources for Teaching
}

\author{
Ahmed Tajudeen Shittu \\ Federal University of Technology Minna, Nigeria \\ Bamidele Wahab Kareem \\ Federal University of Technology Minna, Nigeria \\ Omotayo Olabo Obielodan \\ University of Ilorin, Nigeria \\ Michael Ayodele Fakomogbon \\ University of Ilorin, Nigeria
}

\begin{abstract}
This study examined predictors of pre-service science teachers' behavioral intention toward eresources use for teaching in Nigeria. The study used cross-sectional survey research method and a questionnaire with a set of items that measure technology preparedness, perceived usefulness, perceived ease of use and behavioral intention to gather the data of the study. The sample of the study is comprised of 124 pre-service science teachers graduating from a teacher education program in a Nigerian university. The research instrument of the study was subjected to validity and reliability check. Structural Equation modeling and t-test analysis was used to test the hypotheses of the study and the data collected were used to fit the specified model of the study. The findings of the study showed that technology preparedness does not statistically influence students' behavioral intention towards e-resources use for teaching, but perceived usefulness and perceived ease of use does. The study also revealed that significant difference exists between male and female pre-service teachers behavioral intention towards e-resources use for teaching. Thus, the findings of the study confirm the validity of technology acceptance model construct and provide evidence that technology preparedness of pre-service teacher is inadequate to induce their behavioral beliefs toward future use of e-resources for classroom practice
\end{abstract}

Keywords: Pre-service teachers, E-resources, Perceived usefulness, Ease of use, Behavioral intention

\section{Introduction}

The digital revolution has arguably transformed every area of human discipline. The revolution did not sphere education, rather, it has brought a radical change into how knowledge is created, generated, communicated, stored and used. For pedagogical practice, the technology has brought 
a paradigm shift to how teaching is conducted and how students learn. The development of electronic resource has reshaped the responsibility of professional teachers. Despite the advocacy on the need to deploy information technology resources for teaching and learning, evidence still shows that there is little use of e-resources in the classroom especially in the less developed nations (Clark, 2000; Ertner, 1999; Yusuf \& Balogun, 2011).

Preparing pre-service teachers for the current digital era, teacher educators should be seen to be a key factor in using e-resources for training the future teachers. E-resource are materials, learning content, and information that are in digital form which can only be access through computer. The emergent of e-resources has tremendously influence information creation, handling and usage in education. It enable innovation in teaching and learning, increases discovery and creation of new field of inquiry. To Ray and Day (1998), e-resources is a digital resources that offers students of this generation new opportunities that were not available to previous generations of students. Added to that, Okello-Obura and Magara (2010) noted that e-resources has a lot of advantages over printed resources among these advantages of e-resources are: ease of use, speed, access to multiple files at the same time, access to document outside the library among others.

Given the importance of teacher in the application of e-resources for teaching and learning, researchers have turned their attention to understand the adequacy of teachers' preparation program, whether teacher are well prepared or not to use information communication technology resources for teaching. Findings from these studies have identified factors affecting teachers use of e-resources, among such factors is the inadequacy in the teachers' preparation program (Gill \& Dalgarno, 2008). Providing insight into pre-service teacher preparedness toward use of information technology resources for teaching, Granger, Morbey, Owston and Widersman (2002) suggested a list of contributing factors, which include teacher attitude, philosophies and access to skill training. Supporting the view, Wang (2002) asserted that pre-service teacher beliefs and perception is also very important in shaping future teacher behavior toward e-resources use.

Another issue of interest is on the effect of gender of pre-service teacher towards technology use. Few studies have examined this in the cultural setting of this study, for instance, Yusuf and Balogun (2011) carried out a study on pre-service teachers' competency and attitude towards information technology use in a Nigerian university and established that there is no significant difference between male and female pre-service teacher attitude towards ICT use. Evidence from other studies (Deibyshire, 2003; Kadel, 2005; Schaumburg, 2011; Seyrin, 2005) also revealed existence of differences between male and female attitude toward technology use. While there are fewer study on student attitude towards technology uptake for teaching in Nigeria (Jegede \& Owolabi, 2005; Yusuf, 2005, 2008; Yusuf \& Balogun 2011) the issue bordering on pre-service teachers' subjective probability towards e-resources for future pedagogical practice in Nigeria is yet to be fully explored.

Due to the stated factors and the influence of teacher preparation, it is important to understand whether pre-service teachers are well groomed to take up e-resource for teaching and to know their perception with regards to their behavioral intention toward future e-resources use in the present setting of this study, more so that there is dearth of empirical evidence on pre-service teacher intention towards digital resources use when they get to the field of practice 


\section{Literature Review}

There is growing concern in the recent time on how pre-service teachers received their training for techno-pedagogical practice. Given the role of teachers to nation educational development, such concern cannot be ignored given the rapid advancement in the use of electronic resources in all field of human endeavor. As a result of this, recent research has been geared toward understanding how pre-service teachers were faring in terms of how they are prepared for the challenge of using electronic resources. While some researchers were of the view that willingness to integrate eresources for teaching reside on how pre-service teacher is prepared for uptake of these resources, some were of the opinion that levels of confidence arising from pre-service teacher self-efficacy influence their beliefs of perceived of usefulness of electronic resources for classroom practice (Spaulding, 2016; Ma, Lai, William, Prejan \& Ford, 2008).

Given the importance of using new innovation for classroom practice, Russel, Bebell, O'Dwyer and O'Comer (2003) indicated that part of preparing teacher for contemporary school system is to have teacher educators who are technologically and pedagogically groom to use technology as part of their instructional practice. Providing insight on what influence the use of e-resources among preservice teachers by Wang (2002), in that study, it was noted that student teacher beliefs and perception of how they are prepared will play a crucial role in determined their future electronic resources use for teaching function.

Many researchers have come up with models to explain acceptance of information communication technology (ICT's). Among such model is Technology Acceptance Model (TAM) developed by (Davis, 1989). Technology acceptance model (TAM) take its root from theory of reason action (TRA) developed by Ajzen and Fishbein (1980), an intention to exhibit a behavior is a function of attitude toward such behavior. Individual attitude will predict his/her intention, while the intention will shape the actual behavior. Davis (1989) adapted this idea from TRA to evolve a model. From the original TAM, Davis posited that acceptance to use an information system was a function of two major factors. That is perceived usefulness (PU) and ease of use (EOU) of such system. In one of the study conducted by Davis, Bagozzi and Warshaw (1989) it was reported that beliefs of perceived usefulness and ease of use was a strong determinant of user intention toward use of computer system. According to Davis, perceived usefulness mean "degree to which a user believes that using a particular system would enhance his or her job performance" while perceived ease of use is the degree to which a particular system is free of effort" (Davis et al, p.320).

Recent research has confirmed the strength and validity of perceived usefulness and ease of use as a determinant of users' beliefs about integrating technology for accomplishment of a task (Wozney, Venkatesh, \& Abraimi 2006). In a study conducted by Bozdogan and Ozen (2014) on factors affecting use of information communication technology among pre-service teachers, it revealed that majority of the participants found themselves to possess self-efficacy in deployment of ICT for teaching due to their training. Also they perceived the tool useful, which in-turn increase their confidences in future use of ICT for professional practice. In another similar study conducted by Teo and Schaik (2009) on modeling technology acceptance among pre-service teacher in the National Institute of Education in Singapore, the study reported that perceived usefulness and perceived ease of use significantly influence behavioral intention. The study provides evidence to the validity of TAM predicting strength on acceptance of technology for teaching. 
Several researchers have also empirically attested to the explanatory strength of TAM as a model for understanding user acceptance decision (Davis et al. 1989; Adam, Nelson, \& Todd, 1992; Venkatesh \& Davis, 2000; Lee, Kozar, \& Lorsen, 2003; Venkatesh \& Bala, 2008; Fathema, Shanon \& Ross, 2015). Also, TAM has been profoundly employed to study technology adoption decision across different organizational setting. For example, Hu, Clark and Ma (2003) used TAM to gauge in-service teachers' acceptance of presentation software. Similarly, Kiraz and Ozdemir (2006) used TAM to determine the educational ideologies of pre-service teacher technology acceptance and Wu, Chang, and Guo (2008) used the model to understand science teachers' intention towards technology integration.

Most recent research on user acceptance has produced a variety of explanatory and predictive model (Echeng \& Usori, 2014; Fathema et al., 2016; Mazman, \& Usluel, 2010; Shittu, Gambari, Gimba \& Ahmed, 2016) to explain and extend TAM as new technology come into existence. Since TAM has its shortcoming despite its parsimony this explain why other researcher choose to extend the model by adding other construct to gain more insight on adoption decision of users on new technology

Given the important of human factor in terms of their beliefs, attitude and perception towards technology acceptance and the role of previous knowledge and computer self-efficacy on attitude and beliefs formation, couple with the saying that you can only give what you have. The study therefore set to empirically set to ascertain the influence of information technology preparedness, perceived usefulness and perceived ease of use on pre-service teacher behavioral intention towards use of e-resources for future professional practice. To achieve this, a conceptual model in (figure 1) was developed for the study.

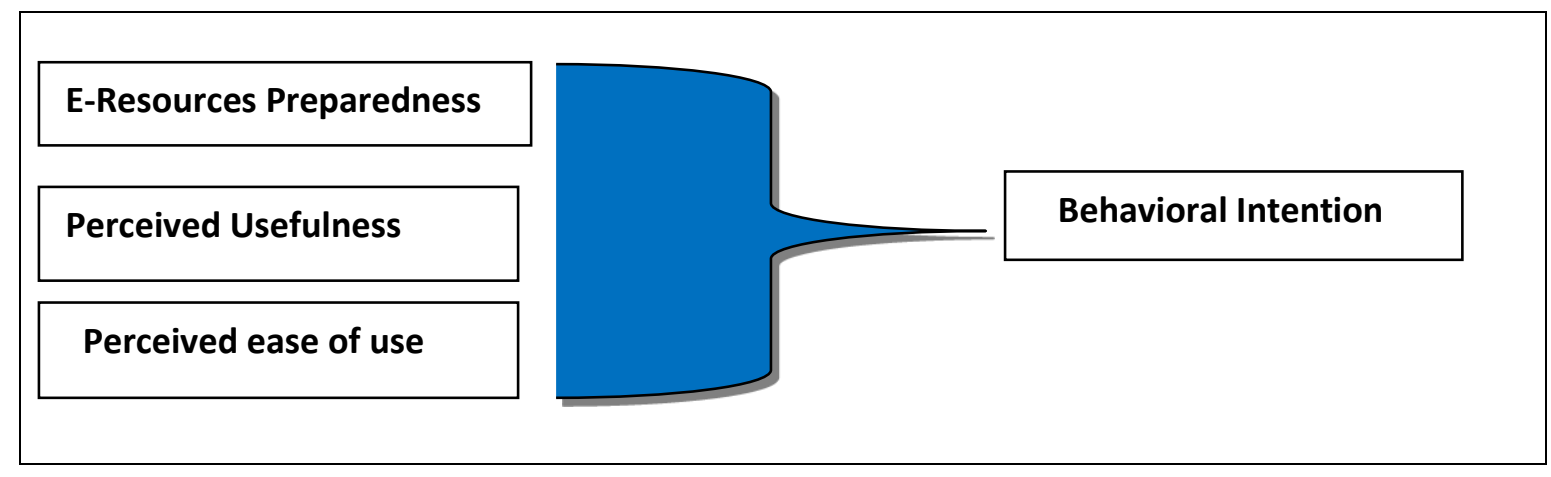

Figure 1. Conceptual Framework of the Study

\section{Hypotheses}

The following alternate hypotheses were raised based on the conceptual framework and the purpose of the study

H1: Pre-service teacher technology preparedness will influence their behavioral intention toward acceptance of e-resource for future teaching practice. 
H2: Perceived usefulness will influence pre-service behavioral intention toward acceptance of eresources for future teaching practice

H3: Perceived ease of use will influence pre-service behavioral intention toward acceptance of eresources for future teaching practice

H4: There will be significant difference between male and female pre-service teacher behavioral intention towards e-resource for teaching

\section{Research Method}

The purpose of this study is to test a model that predicts behavioral intention toward e-resource use among pre-service teacher in the Department of science education of Federal University of Technology Minna, Nigeria and to ascertain if significant difference exists between male and female pre-service teachers behavioral intention towards e-resources use for future professional practice. To achieve the objective of the study, a structural equation model (SEM) was used for analyzing the data of the study. Also, t-test statistical analysis was carried out to verify if difference exist between male and female pre-service teacher behavioral intention towards e-resources use for teaching after graduation. The instrument of the study consisted of a set of four (4) latent variables: technology preparedness, perceived usefulness, perceived ease of use and behavioral intention. The collected data were subjected to correlation and covariance analysis so as to determine the degree at which the proposed model replicates the correlation of the indicators of the variable.

The population for the study was comprised of 210 graduating students of the Department of Science Education. The data collected from the sample was used to fit the specified model of the study. In fact, to test a model with SEM, sample size is very important (Teo, Su Luan \& Sing 2008). Due to the importance of the sample size, Bollen (1989) recommended a minimum sample of 100 to fit a model, Anderson and Gerbing (1988) recommended a minimum of 200 samples, but Hair et al. (2006) were of the view that any study with five or fewer construct, with more than three items on each construct and high item communality with .60 and higher can adequately be estimated with sample size of 150 . In the present study, the final sample was comprised of 124 students, representing $59 \%$ of the total population. The instrument used consisted of four (4) constructs with thirty (30) items. Out of these items (10) was an indicator four measuring e-resources preparedness; eight (8) of the items were an indicators for measuring perceived usefulness; seven (7) were an indicator for measuring ease of use and five (5) items were used for measuring behavioral intention. The respondents were asked to respond to 7-point Likert type scale ranging from 1 Strongly disagree to -7-Strongly agree. All items were slightly modified and subjected to a validity and reliability check.

Table 1. Descriptive Statistic of the Items; Mean, Standard Deviation, Skewness and Kurtosis

\begin{tabular}{ccccc}
\hline Items & Mean & Std dev & Skewness & Kurtosis \\
\hline PRE1 & 4.57 & 2.10 & -.56 & -1.13 \\
PRE2 & 4.85 & 2.13 & -.68 & -1.09 \\
PRE3 & 4.51 & 2.12 & -.47 & -1.24 \\
PRE4 & 5.07 & 1.93 & -.87 & -.52 \\
\hline
\end{tabular}




\begin{tabular}{ccccc}
\hline PU1 & 5.14 & 1.86 & -.1 .01 & -.09 \\
PU2 & 5.51 & 1.77 & -.1 .28 & -63 \\
PU3 & 5.35 & 1.67 & -.16 & .44 \\
PU4 & 5.38 & 1.71 & -.1 .07 & .23 \\
PU5 & 5.45 & 1.76 & -.1 .12 & .09 \\
PU6 & 5.43 & 1.70 & -.1 .22 & .58 \\
PEU1 & 4.88 & 1.87 & -.84 & -.38 \\
PEU2 & 5.02 & 1.79 & -.83 & -.33 \\
PEU3 & 4.90 & 1.89 & -.63 & .37 \\
PEU4 & 5.00 & 1.80 & -.85 & -.27 \\
BI1 & 5.40 & 1.65 & -.1 .25 & .89 \\
BI2 & 5.14 & 1.78 & -.88 & -.22 \\
BI3 & 5.20 & 1.73 & -.1 .16 & .54 \\
\hline
\end{tabular}

Table 2. Principal Component Analysis, Composite Reliability and AVE

\begin{tabular}{|c|c|c|c|c|c|}
\hline Items & $\begin{array}{l}\text { Factor } \\
\text { loading }\end{array}$ & Eigenvalue & $\begin{array}{l}\text { \% of } \\
\text { Variance }\end{array}$ & $\begin{array}{l}\text { Composite } \\
\text { Reliability }\end{array}$ & $\begin{array}{l}\text { Average } \\
\text { Variance } \\
\text { Explain }\end{array}$ \\
\hline PRE1 & .67 & & & & \\
\hline PRE2 & .61 & & & & \\
\hline PRE3 & .67 & & & & \\
\hline PRE4 & .66 & 12.43 & 41.44 & .79 & 54 \\
\hline PU1 & .57 & & & & \\
\hline PU2 & .62 & & & & \\
\hline PU3 & .59 & & & & \\
\hline PU4 & .77 & & & & \\
\hline PU5 & .76 & & & & \\
\hline PU6 & .70 & 2.33 & 7.77 & .91 & 52 \\
\hline PEU1 & .70 & & & & \\
\hline PEU2 & .73 & & & & \\
\hline PEU3 & .54 & & & & \\
\hline PEU4 & .62 & 1.42 & 4.73 & .83 & 50 \\
\hline $\mathrm{BI} 1$ & .49 & & & & \\
\hline $\mathrm{B} 12$ & .53 & & & & \\
\hline $\mathrm{BI} 3$ & .62 & 1.24 & 4.15 & .79 & 50 \\
\hline
\end{tabular}

The total variance accounted for is $58 \%$; $\mathrm{KMO}=.90$, Sig= .00; Barlet test of Spericity $=2846.87$; $\mathrm{df}=.56$ 


\section{Descriptive Analysis}

In line with the objective of the study which aimed to fit the data collected to the specify model, the descriptive statistic for each variable was computed to ascertain the normality of the data to structural equation modeling as shown in Table 1. All the mean of the items were greater than 4.0, the mean range from 4.51 to 5.51 , while the standard deviation was between 2.13 to 1.65 . This indicated an overall positive response to the variables of the study. The Skewness and Kurtosis were computed and skewness range from- -1.28 to -.49 , while Kurtosis range from -1.24 to -.09 , with this output, the data were considered normal (Teo et al, 2009).

\section{Validity and Reliability of the Data}

To ascertain the convergent validity of the instrument, item by item reliability was checked through the factor loading, also composite reliability of each variance and average variance extracted were computed (Fornell \& Larcker, 1981). In Table 2 was the principal component analysis of the four (4) variables of the study. The computation revealed a total variance of $58 \%$ with eigenvalue greater than one (1), KMO which is measure of sample adequacy was .90, Barlet test of spericity was 2846.874 (Nunnally \& Bernstein, 1994). A check on each of the indicators revealed the reliability strength of the construct. In line with Hair, Black, Babin, Anderson, \& Tatham (2006) suggestion, an item is high if the factor loading on it is greater than 0.60. A check on the factor loading revealed that most of the items met the threshold except PU3, PEU4 and BI1, other items exceed the threshold set by Hair et al. (2006). The computation shows that the data demonstrated convergent validity.

The composite reliability of the variable was computed using Cronbach Alpha. Any alpha value above .70 is considered acceptable (Teo, 2009; DeVellie, 2007; Shaver \& Wrightsman, 1991). The reliability of the constructs in Table 2 exceeded the recommended value, the alpha value for each of the variable range from .79 to .91 . 
Table 3.Correlation Matrix and Measure of Average Variance Extracted

\begin{tabular}{|c|c|c|c|c|c|}
\hline & & E-resources & PUSE & PEOU & BINT \\
\hline \multirow[t]{2}{*}{ E-resources } & Pearson Correlation & (58) & & & \\
\hline & & 124 & & & \\
\hline \multirow[t]{3}{*}{ PUSE } & Pearson Correlation & $.683^{* *}$ & $(.70)$ & & \\
\hline & & .000 & & & \\
\hline & & 124 & 124 & & \\
\hline \multirow[t]{3}{*}{ PEOU } & Pearson Correlation & $.502^{* *}$ & $.514^{* *}$ & (.68) & \\
\hline & & .000 & .000 & & \\
\hline & & 124 & 124 & 124 & \\
\hline \multirow[t]{3}{*}{ BINT } & Pearson Correlation & $.518^{* *}$ & $.631^{* *}$ & $.653^{* *}$ & $(.72)$ \\
\hline & & .000 & .000 & .000 & \\
\hline & & 124 & 124 & 124 & 124 \\
\hline
\end{tabular}

**. Correlation is significant at the 0.01 level (2-tailed).

\section{Discriminant Validity of the Data}

The discriminant validity check on the construct led to computation of correlation analysis and average variance extracted (AVE). Discriminant validity is computed to measure the extent to which the variable of the study differ from one another. In this study discriminant validity was assessed by comparing the square root of the AVE for a specific variable with the correlation between the variable and other variable of the study. Table 3 above shows the correlation matrix, while the diagonal value was replaced with average variance extracted (AVE). To inspect the discriminant validity therefore, the diagonal value should be greater than off diagonal value in the corresponding row and columns (Fornel, Tellis \& Zinkham, 1982; Teo, 1990). A check on Table 3 showed that all value in the diagonal is greater than off diagonal value which indicated the existence of discriminant validity. 


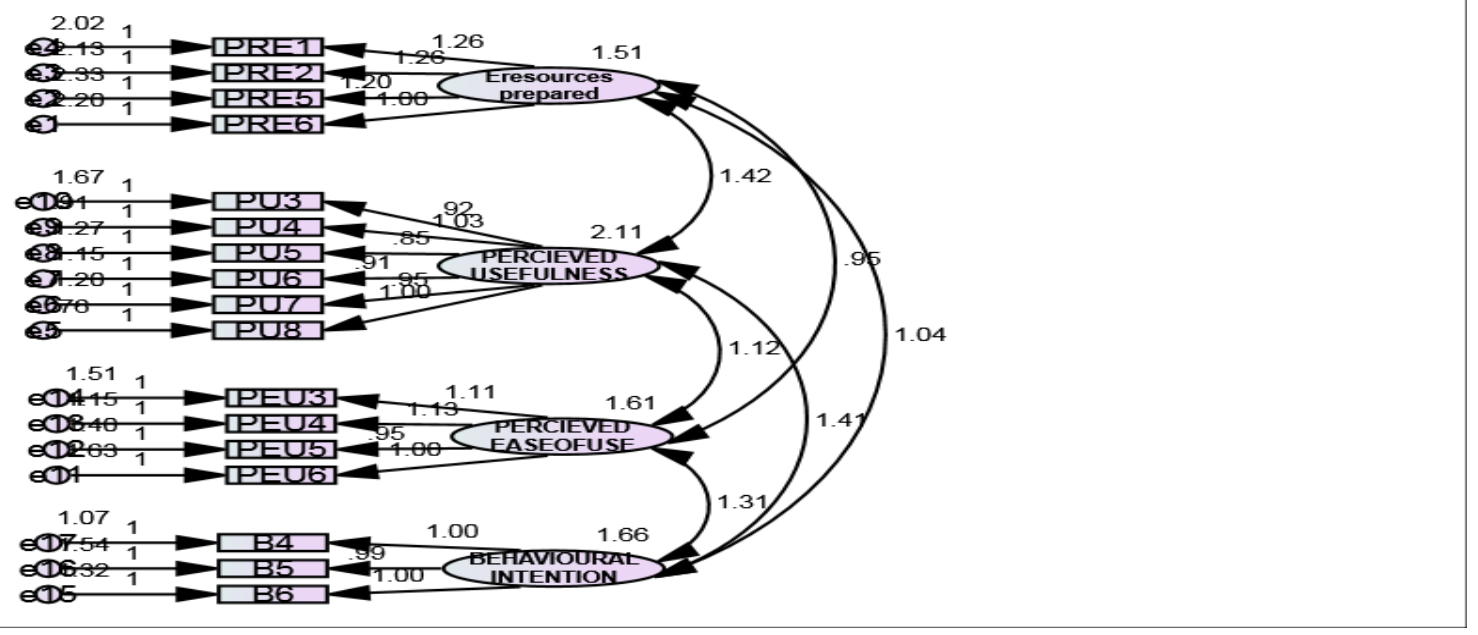

Figure2. The Measurement Model

\section{Assessing Model and Hypotheses Testing}

The research model of the study was analyze through structural equation modeling approach. The fit indices used for analyze was suggested by Hair at al, (2006). The indices include absolute fit indices that measure the overall degree of discrepancy between implied and observed covariance matrices. The indices include the $\left(\mathrm{X}^{2}\right)$ statistic and parsimonious indices which is similar to absolute fit indices. The most widely used parsimonious indices is root mean square error of approximation (RMSEA). The last set of indices used to ascertain the fitness of the model was suggested by Kline (2005), the indices is incremental fit indices, they are comparative fit index (CFI) and Turker-Lewis index (TLI).

Prior to final fit of the model of the study, the measurement model was evaluated and the measurement model in (fig 2) demonstrated an acceptable fit for structural equation modeling analyses. A final computation of structural equation modeling (SEM) revealed that the data of the study adequately fit the specify model with the following indices $p=.00$; RMSEA $=.068$; $C F I=.943$; $\mathrm{TLI}=.932$.

In testing the hypotheses of the study, the regression path was check and the value on the effect size revealed the following: the first hypothesis, that state that Pre-service teacher technology preparedness will influence their behavioral intention toward acceptance of e-resource for future teaching practice, showed $(\beta=-.03, p<.001)$ with this result the hypothesis was not supported. The second hypothesis that states Perceived usefulness will influence pre-service behavioral intention toward acceptance of e-resources for future teaching practice revealed a statistically significant influence with effect size $(\beta=0.40, p<.001)$. The third hypothesis that state that Perceived ease of use will influence pre-service behavioral intention toward acceptance of e-resources for future teaching practice revealed a statistically significant influence with effect size $(\beta=0.55, p<.001)$. The second and third hypotheses stand validated, while the first hypothesis was statistically 
insignificant. The three constructs of the study collectively explain forty percent (40\%) influence on student behavioral intention towards e-resources for teaching. With these findings, there are other salient factors not capture that could influence pre-service teacher behavioral intention towards eresources for teaching. Table 4 below is the summary of the result emanated from the model of the study.

Table 4. Summary of the Result of Hypotheses Tested

\begin{tabular}{cccc}
\hline Hypotheses & Path & Path coefficient & Results \\
\hline H1 & EPRE $\rightarrow$ BINT & -.03 & Not supported \\
H2 & PU $\rightarrow$ BINT & 0.40 & Supported \\
H3 & PEU $\rightarrow$ BINT & 0.55 & Supported \\
\hline
\end{tabular}

$p<.005$

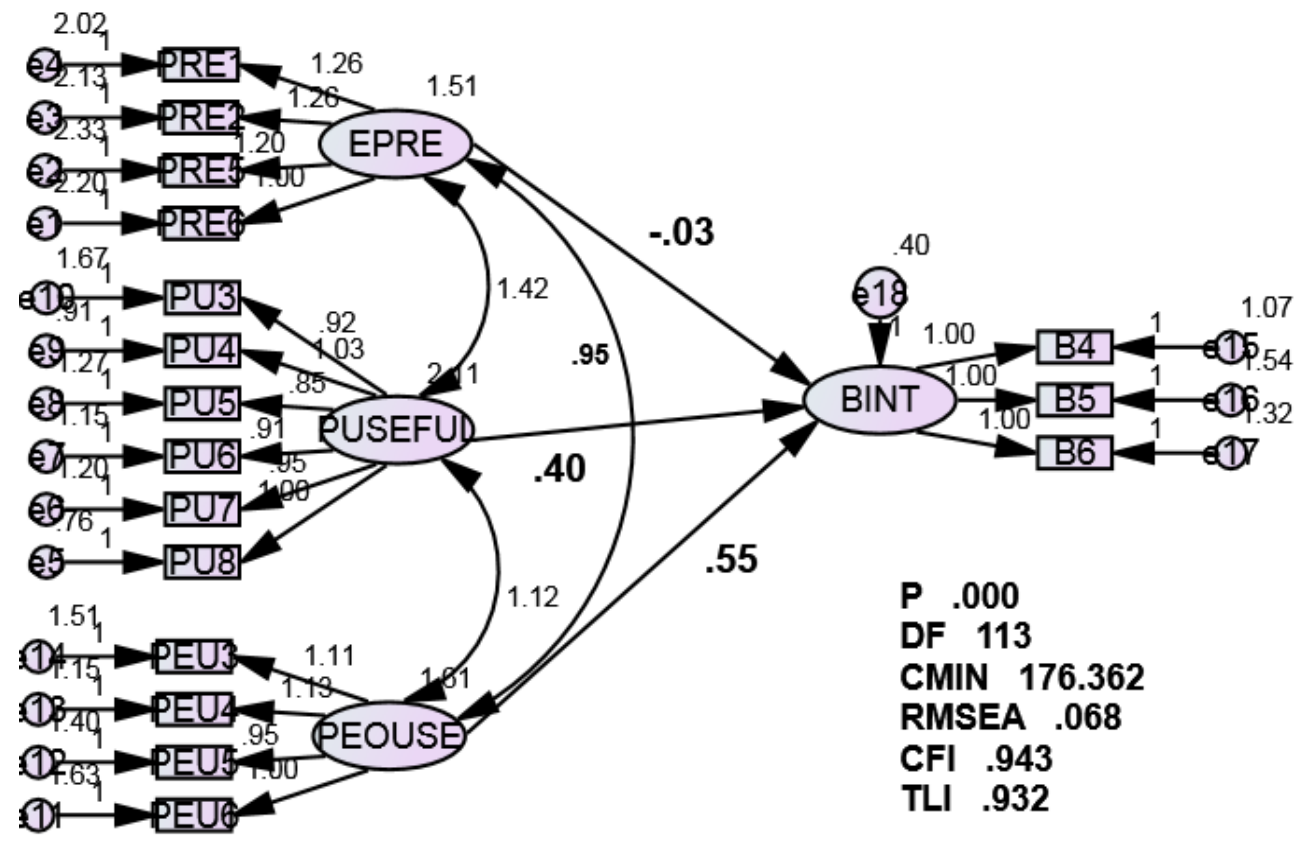

Figure 3. The Structural Model of the Study

H5: There will be significant difference between male and female pre-service teacher behavioral intention towards e-resource for teaching 
Table 4. Mean and Standard Deviation of Male and Female Behavioral Intention Towards e-resources use for Teaching

\begin{tabular}{llcccc}
\hline & SEX & N & Mean & Std. Deviation & Std. Error Mean \\
\hline Behavioral Intention & MALE & 79 & 32.1899 & 7.70959 & .86740 \\
& FEMALE & 44 & 29.2045 & 8.85958 & 1.33563 \\
\hline
\end{tabular}

Table 5.t-testAnalysis of Difference between Male and Female Pre-service Teachers' Behavioral Intention towards E-Resources Use

\begin{tabular}{|c|c|c|}
\hline & \multirow{2}{*}{\multicolumn{2}{|c|}{$\begin{array}{c}\text { Explain } \\
2.38\end{array}$}} \\
\hline \multirow{2}{*}{$\begin{array}{l}\text { Levene Test for equal } \\
\text { of variance }\end{array}$} & & \\
\hline & Sig & .126 \\
\hline t-test for equality & $\mathrm{t}$ & 1.950 \\
\hline \multirow[t]{5}{*}{ of mean } & Df & 121 \\
\hline & Sig (2tailed) & .053 \\
\hline & Mean different & 2.98 \\
\hline & 95\% (confidence & Lower $\quad-04407$ \\
\hline & interval) & 6.05662 \\
\hline
\end{tabular}

$\mathrm{p}<.005$

Result of finding on the hypothesis that sought to understand if significant difference exists between male and female pre-service teachers' behavioral intention towards e-resources use for future professional practice revealed in (Table 4 and 5) that there is significant difference between the two groups, with male $(M=32.18, S D=7.709)$ and Female $(M=29.20, S D=8.8596), t(121)=1.95, p=.053$. $A$ further analysis of the effect size (d) between the group according to Cohen (1988) interpretation, an effect size of $d=2$ is consider small, $d=5$ is medium, while $d=8$ and above is considered large effect size. Analysis of the effect size between the groups which aims at ascertains the magnitude of the difference and how practical important is the difference showed $d=0.36$, with this result the difference is considered to be a small effect, neither too small nor large effect exist between the groups.

\section{Discussion and Conclusion}

In line with the objective of the study which set to examine the influence of technology preparedness, perceived usefulness, perceived ease of use on pre-service teacher behavioral intention toward use of e-resources for future teaching practice. The finding of the study showed that the first hypothesis was statistically not supported. The finding was at variant with Wang (2002) study which reported that pre-service teachers' technology preparedness would significantly influence their future deployment of information technology in the classroom. Conversely, the finding supported earlier observation raised by Brzycki and Dudt (2005); Sulton (2011) that the 
technology preparation of pre-service teacher is insufficient to induce their future integration of information technology for professional practice.

The second hypothesis was statistically validated. The finding showed that the beliefs of perceived usefulness would influence pre-service teacher behavioral intention toward e-resources use. This finding supported the finding of Davis et al, (1989) that submitted that the beliefs of perceived usefulness is a strong determinant of acceptance to use information system. The study also supported the finding of Teo and Schaik (2009) which model acceptance of IT for teaching among Singaporean pre-service teacher and found that the beliefs of usefulness is a precondition for acceptance of information technology for teaching among pre-service teachers.

The third hypothesis also stands validated. The finding showed that belief of ease of use would influence pre-service teacher behavioral intention toward e-resource use. The finding also supported Davis (1986) study on the strength of ease of use as a determinant of information system use among end users. The present finding concurred with Bozdogan and Ozen (2014) finding that concluded that ease of use of technology would influence acceptance of information technology use for teaching among pre-service teacher. The last hypothesis that sought to established whether significant difference exist in the behavioral intention of male and female pre-service teacher toward e-resources use for future professional practice revealed a slight significant difference between the two groups in terms of their future attitude towards e-resources use for teaching. In fact, in terms of practical importance and magnitude, the difference is a small effect. Notwithstanding, the finding was in congruent with Yusuf and Balogun (2011) findings that revealed the existence of no difference between male and female pre-service teachers attitude towards ICT. However, the finding partially support the finding of Derbyshire (2003); Sefyrin (2005); Kadel, (2005) findings of difference between male and female teachers attitude towards information technology use for pedagogical practice. With this empirical evidence, it is therefore important to stress that teacher educator need to intensify their effort to train the pre-service teacher with both technological and pedagogical knowledge required for them to survive in the labor market; train the trainer workshop should be organize periodically for teacher educators on new trend in providing quality training in terms of effective and efficient use of e-resource for implementing teacher education program. With the finding of this study, if teacher preparation program of the university integrate technology into the training of pre-service teacher, such training would strengthen the antecedent of usefulness and ease of use which will in-turn equip the graduate of the university with all round skill required of the $21^{\text {st }}$ century teachers.

\section{Limitations}

Like other similar case study, this study also has its limitations. Part of it limitation is the generalization of the finding of the study beyond the scope and the population of the study, which is the pre-service teachers in a Nigerian University. Therefore the finding cannot be generalized beyond the population of the study and the phenomenon considered. Another limitation of the study can be located in the sample size considering the methodology used to prosecute the study. The sample of the study was above 100 and less than 150, while some researchers were of the opinion that a sample size above 100 is sufficient for SEM analysis, some were of the strong opinion that sample size of 150 and above is most appropriate for a robust SEM analysis. Lastly, the combine 
strength of the independent variable of the study can only explain $40 \%$ variance on the dependent variable, by implication there are other salient factors unexplained which is not capture in this study that other researchers can explored.

\section{References}

Adam, D. A., Nelson, R. R., \& Todd, P. A. (1992). Perceived usefulness, ease of use, and usage of information technology: a replication, MIS Quarterly, 16, 227-247.

Anderson, J. C. \& Gerbing, D. W. (1988). Structural equation modeling practice: A review and recommended two-step approach. Psychological Bulleting, 103(3), 411-423.

Bollen, K. A. (1989). Structural equations with latent variables, New York: John Wiley.

Bozdogan, D. \& Ozen, R. (2014). Use of ICT technologies and factors affecting pre-service ELT teachers' perceived ICT self-efficacy, The Turkish Online Journal of Educational Technology, $17(2), 186-196$.

Clark, K. F. (2000). Urban middle school teachers' use of instructional technology. Journal of Research in Computing in Education, 33(2), 1-18.

Cohen, J. (1988). Statistical power analysis for the behavioural sciences $\left(2^{\text {nd }} e d\right)$. Hillsdale, NJ: Lawrence Earlbaum Associate.

Davis, E. (1986). A technology acceptance model for empiricall testing new end-user information system: theory and results (Unpublished doctoral dissertation). Sloan School of Management, Massachusetts Institute of Technology. Cambridge, MA.

Derbyshire, H. (2003). Gender issue in the use of computers in education in Africa. Retrieved on 2 January 2016 from http://unfundo.digital/brain.com/imfundo/web/learn/document

Echeng, R. \& Usoro, A. (2014). Acceptance factors and current level of use of web 2.0 technologies for learning in higher education: a case study of two countries. International Journal of Advance Computer Science and Application, 5(5), 9-14.

Ertmer, P. A. (1996). Addressing first and second order barriers to changes: Strategies for technology integration. Educational Technology Research and Development, 47(4), 47-61.

Fathema, N. \& Shannon, D. (2015). Expanding the technology acceptance model (TAM) to examine faculty use of learning management syatem in higher institution. MERLOT Journal of Online Learning and Teaching, 11(2), 210-232.

Fornell, C., Tellis, G. J., \& Zinkham, G. M. (1982). Validity assessment: A structural equations approach using partial least squares: AMA Educators. Proceedings (pp.405-409). Chicago, IL.

Gill, L. \& Dalgano, B. (2015). How does pre-service teacher preparedness to use ICTs for learning and teaching develop through their degree program? Australian Journal of Teacher Education, 4(1), 37-54. 
Granger, C., Morbey, H., Owston, R., \&Wilderman, H. (2002). Factor contributing to teachers' successful implementation of information technology. Journal of Computer Assisted Learning, 16, 480-488.

Hair, J. F. Jr., Black, W. C., Babin, B. J., Anderson, R. E., \& Tathan, R. L. (2006). Multivariate data analysis ( $\left.6^{\text {th }} E d\right)$, New Jersey: Prentice-Hall

Hu, P. J., Clark, T. H. K., \& Ma, W. W. (2003). Examining technology acceptance by school teachers: a longitudinal study. Information and Management, 41, 227-241.

Jegede, P.O. \& Owolabi, J. A. (2003). Computer education in Nigeria secondary schools. Gaps between policy and practice.

Kadel, R. (2005). How teacher attitude affect technology. Learning and Leading with technology, 39(5), 34-47.

Kiraz, E. D., \& Ozdenir, D. (2006). The relationship between educational ideologies and technology acceptance in pre-service teachers. Educational Technology \& Society, 9(2), 152-165.

Kline, R. D. (2010). Principle and Practice of structural equation modeling ( $3^{\text {rd }}$ ed). New York: Guildford.

Ma, Y., Lai, G., Williams, D., Prejean, I., \& Ford, M. J. (2008). Exploring the effectiveness of a field experience program in a pedagogical laboratory: The experience of teacher candidate, Journal of Technology and Teacher Education, 16(4), 411-432.

Mazman, S.J., \& Usluel, Y. (2010). Modeling educational usage of Facebook. Computer \& Education, 55, 444-453.

Okello-Obura, C. \& Magara, E. (2010). Electronic information access and utilization by Makerere students in Uganda. Evidence Based Library and Information Practice. 3(3), 15-35.

Ray, K. \& Day, J. (1998). Student attitudes towards electronic information usage. Journal of Information Research, 4(2), 1-26.

Russell, M., Babell, D., O'Connor, K. (2003). Examining teacher technology use: implication for preservice and in-service teacher preparation. Journal of Teacher Education, 54(4), 297-310.

Schaumburg, H. (2001). Fostering girls' computer through laptop learning-can mobile computer help to level out the gender difference? Retrieved on 2 January 2016 from http://citeseerx .ist.psu.edu/viewdoc/download?doi=10.1.1.6.8886\&rep=rep1\&type=pdf

Seyrin, J. (2005). Understandings of gender and competencies in ICT. Paper presented at $6^{\text {th }}$ International Women into Computing Conference. University of Greenwich. Retrieved on 2 January 2016 from http://www.miun.se/upload/institutioner/ITM/IKS/SI/publicationer/ sefyrin_WIC.pdf

Spaulding, M. (2016). Influence of technology skills on pre in-service teachers. Retrieved on 2 January 2016 from http:Ilwww.rissa.w/tech_journal/volume_2.2/vo/2_article8

Teo, T., Su Luan, W., \& Sing, C. C. (2008). A cross-cultural examination of the intention to use technology between Singaporean and Malaysian pre-service teachers: an application of the technology acceptance model (TAM). Educational Technology \& Society, 11(4), 265-280. 
Teo, T. \& Schaik, P. V. (2009). Understanding technology acceptance in pre-service teachers: a structural equation modeling approach, The Asian-Pacific Educational Researcher, 18(1), 4766.

Teo, T. (2010). A path analysis of pre-service teacher attitude to computer use: applying and extending the TAM in an educational context, Interactive Learning Environments, 18(1), 6579.

Ward, L. (2003). Teacher practice and the integration of ICT: why aren't our secondary school teachers use computer in their classroom? Proceedings of the NZARE Conference (pp.1-13). Auckland, New Zealand.

Wozney, I., Venkatesh, V., \&Abrama, P. (2006). Implementing computer technologies: teachers' perception and practice. Journal of Technology and Teacher Education, 14(1), 173-187.

Wu, W., Chang, H., \& Guo, C-J. (2008). An empirical assessment of science teachers intention toward technology integration. The Journal of Computer in Mathematics and Science Teaching, 27(4), 499-520.

Yusuf, M. O. \& Balogun, M. R. (2011). Student-teacher competence and attitude towards information and communication technology: A case study in a Nigerian university. Contemporary Educational Technology, 2(1), 18-26. 


\section{Appendix}

\begin{tabular}{|c|c|}
\hline Constructs & Items \\
\hline Pre1 & The way I am prepare to use digital tool will inform my decision to use it \\
\hline Pre2 & $\begin{array}{l}\text { A good use of digital tool by our instructor will motivate me to use Information } \\
\text { Technology for teaching }\end{array}$ \\
\hline Pre3 & $\begin{array}{l}\text { Failure to use digital tool for teaching by our instructor may not affect my } \\
\text { willingness to use it }\end{array}$ \\
\hline Pre4 & $\begin{array}{l}\text { Preparing us for digital tool driven class should start when we undergo teacher } \\
\text { training }\end{array}$ \\
\hline Pre5 & $\begin{array}{l}\text { How our teacher integrate digital tool for pedagogy activities will prepare us for } \\
\text { its use in future }\end{array}$ \\
\hline Pre6 & $\begin{array}{l}\text { The way I receive my training with digital tool will assist me to use IT for } \\
\text { teaching others }\end{array}$ \\
\hline Pre7 & $\begin{array}{l}\text { I may be discourage to use digital tool for teaching if my instructor fail to use IT } \\
\text { to teach me }\end{array}$ \\
\hline Pre8 & $\begin{array}{l}\text { Whether I see my instructor using digital tool or not, I will try out it usage for } \\
\text { teaching when I become a professional teacher }\end{array}$ \\
\hline Pre9 & $\begin{array}{l}\text { The way I am train, to an extent, will reduce my anxiety toward using digital tool } \\
\text { for teaching }\end{array}$ \\
\hline Pre10 & if I haven't seen the teacher using digital tool I won't use it." \\
\hline PU1 & Digital tool can enhance students' learning \\
\hline PU2 & IT can provide better learning experience \\
\hline PU3 & I would work harder if I could use digital tool \\
\hline PU4 & Digital tool make teaching and learning more interesting \\
\hline PU5 & Digital tool are worthwhile \\
\hline PU6 & Digital tool gives opportunity to learn more \\
\hline PU7 & Digital tool use for teaching can increase productivity \\
\hline PU8 & Digital tool use for teaching can improve effectiveness \\
\hline PEU1 & The use of digital tool for teaching will be easy for me \\
\hline PEU2 & I belief digital tool usage will improve the quality of my teaching \\
\hline PEU3 & My interaction with digital tool is clear and understandable \\
\hline PEU4 & Overall, I am convince that digital tool is easy to use \\
\hline PEU5 & Deploying digital tool for teaching after graduation will not pose any threat \\
\hline PEU6 & With my training, using digital tool for teaching will be easy \\
\hline B1 & I will use digital tool in future \\
\hline B2 & I plan to use digital tool during my teaching practice \\
\hline B3 & When never possible, I intend to use digital tool for teaching \\
\hline B4 & I will strongly recommend other to use IT for teaching and learning \\
\hline B5 & Baring any challenge, I can predict that I would use IT for teaching \\
\hline B6 & $\begin{array}{l}\text { If IT facility is provided in my school, I will take maximum advantage of using IT } \\
\text { for teaching }\end{array}$ \\
\hline
\end{tabular}

Correspondence: Ahmed Tajudeen Shittu, Ph.D., Department of Educational Technology, Federal University of Technology, Minna, Nigeria 